\title{
Control BLDC Motor Speed using PID Controller
}

\author{
Md Mahmud ${ }^{1}$, S. M. A. Motakabber ${ }^{2}$, A. H. M. Zahirul Alam³, Anis Nurashikin Nordin ${ }^{4}$ \\ Department of Electrical and Computer Engineering \\ International Islamic University Malaysia \\ Kuala Lumpur, Malaysia
}

\begin{abstract}
At present, green technology is a major concern in every country around the world and electricity is a clean energy which encourages the acquisition of this technology. The main applications of electricity are made through the use of electric motors. Electric power is converted to mechanical energy using a motor, that is to say, the major applications of electrical energy are accomplished through electric motors. Brushless direct current (BLDC) motors have become very attractive in many applications due to its low maintenance costs and compact structure. The BLDC motors can be substituted to make the industries more dynamic. To get better performance BLDC motor requires control drive facilitating to control its speed and torque. This paper describes the design of the BLDC motor control system using in using MATLAB/SIMULINK software for Proportional Integral Derivative (PID) algorithm that can more effectively improve the speed control of these types of motors. The purpose of the paper is to provide an overview about the functionality and design of the PID controller. Finally, the study undergoes some well-functioning tests that will support that the PID regulator is far more applicable, better operational, and effective in achieving satisfactory control performance compared to other controllers.
\end{abstract}

Keywords-PID controller; green technology; fuzzy logic control; speed control; BLDC motor

\section{INTRODUCTION}

The present era is the era of the industrial revolution, which began with the invention of motor. Various types of motors have been developed over time, but these motors are generally classified into two main categories, namely, AC motor and DC motor. There exists a set of DC motors that can be used on different devices. However, generally two types of DC motors are set up in industrial applications. In the first type, the magnetic flux is generated by the current through the field coil of static pole structure and in the second type, permanent magnet supplies the required air gap flux [1]. A BLDC motor is a special type of DC motor that does not apply a brush for transport, instead an electronic process system is used for this purpose. The BLDC motor is usually a synchronous motor composed of a trapezoidal back EMF waveform and a permanent magnet. The current trend shows that highperformance BLDC motor technologies are widely used for global industrial applications and variable speed drives in electric vehicles [2]. In fact, these types of motors depend on its control circuit. In fact, these types of motors rely on its control circuit and still developing a high performance circuit is a challenging task for researchers. A basic control system is shown in Fig. 1 for the BLDC motor.
The structure of the BLDC motor tuning control project selection, modelling simulation and so on. The design structure of a BLDC motor is a complex task and depends on many issues such as project selection, modeling, simulation, etc. In terms of the rapidity framework of the BLDC motor, a host of modern control solutions have been proposed [3].

The key features of a conventional PID controller algorithm are it is easily adjustable, steady operation and its simple design, which making it widely used for controlling system. For practical reason, common speed control structure is applied in the PID controller. The mathematical model and speed control of the BLDC motor have been proposed and validated using fuzzy logic and PID controller [4]. Most of the cases a different finding is seen in terms of practical utility experiences where the volatility of well-structured prototype, different units of nonlinear, low variability have been at work. For tuning a PID controller parameters are not that simple, hence, getting the optimal position under the examined circumstances is challenging [5]. This study proposes a PID controller through modifying some changes thereto which, may increase the regulation speed of BLDC motor. In this case parameters can be tuned at the actual moment under PID controller operation. In the sake of better functioning of the PID controller scheme requires input and membership function enhancement [6]. At the same time, a set of values are applied for the PID controller's constant coefficients, $K_{p}, K_{i}$ and $K_{d}$. By employing these values, the proposed modified controller would be restructured to any adjusting dimension.

The purpose of this study is to show the dynamic response to the rapid tuning results of the proposed modified PID controller; which can help to control the speed of the motor and to maintain constant speed during load changes. Thus, the PID regulator can increase the overall performance of the BLDC motor. The simulation results showed that the functions of the PID controller could be provided with a better control performance [7].

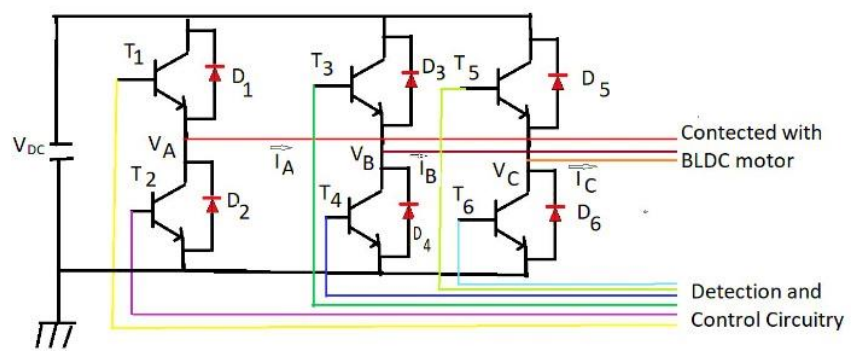

Fig 1. Basic Circuit Diagram for the BLDC Motor Control System. 


\section{BLDC MOTOR AND SPEED CONTROL SYSTEM}

\section{A. Speed Control System}

A controller circuit is essential to operate and control the speed of a BLDC motor. There are many types of speed control system developed for controllers but the speed controllers have to modernize with the ages. However, they are generally classified as closed loop and open loop control systems, respectively. Closed loop techniques are used for high accuracy control system. Fig. 2 shows a BLDC motor speed controller block diagram using two closed loop systems. In this case, the internal loop is used for tuning and sense the power supply polarity and the external loop is used to control the speed. The motor speed controller helps to adjust the voltage of the DC bus. To control the system, DC supply is required and its value depends on the motor speed (rpm) and its capacity. This system also requires a controller, in which case a PID controller is used that ultimately controls the inverter output voltage. A sensor is an integral part of a closed loop controller for controlling the speed of a motor. The primary function of the sensor is to convert the physical position and condition of the motor shaft into an equivalent electrical signal for the controller circuit. Typically, BLDC motor requires an AC-like voltage-waveform for its operation, so inverter circuit is used to convert the DC power supply voltage into an equivalent $\mathrm{AC}$ supply voltage [8], [9] for proper function.

\section{B. The Back Electro Motive Fource (BEMF)}

Typically, a 3-phase BLDC motor uses six electronic switches (power transistors) to produce 3-phase voltage simultaneously to a full-bridge configuration power converter. The transistors have a rotor position, which will be defined as the switching sequence. Most of the cases motor starter is monitoring by using three hall sensor devices. The hall sensors provide the information to the decoder block for producing the sign of reference current signal vector to the back electromotive force (BEMF). To operate the motor in the opposite direction, the current is changed in reverse direction or the switching order of the controller is changed.

The MATLAB simulation block diagram for generating the back EMF of the decoder is shown in Fig. 3, and Table I shows the decoder sequences of the proposed 3-phase PID controller for the BLDC motor to rotate in the clockwise direction.

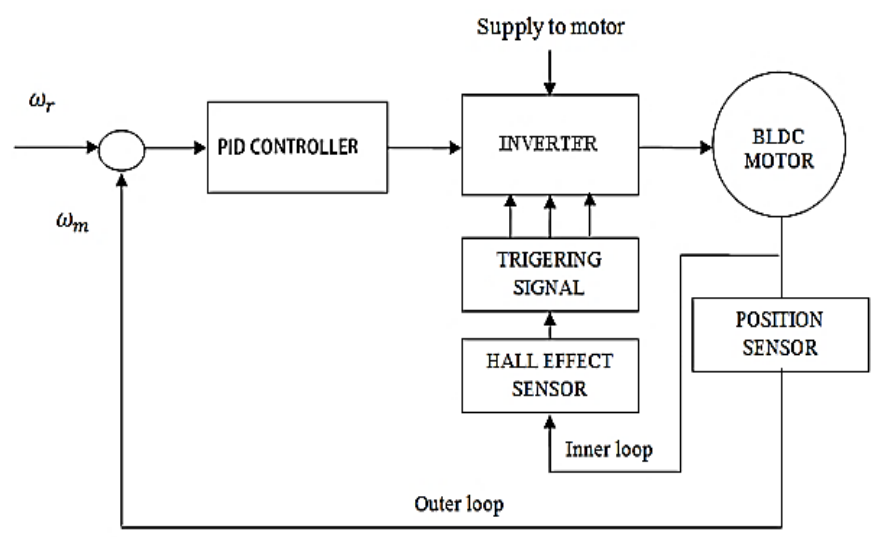

Fig 2. Block Diagram of BLDC Motor Speed Control.

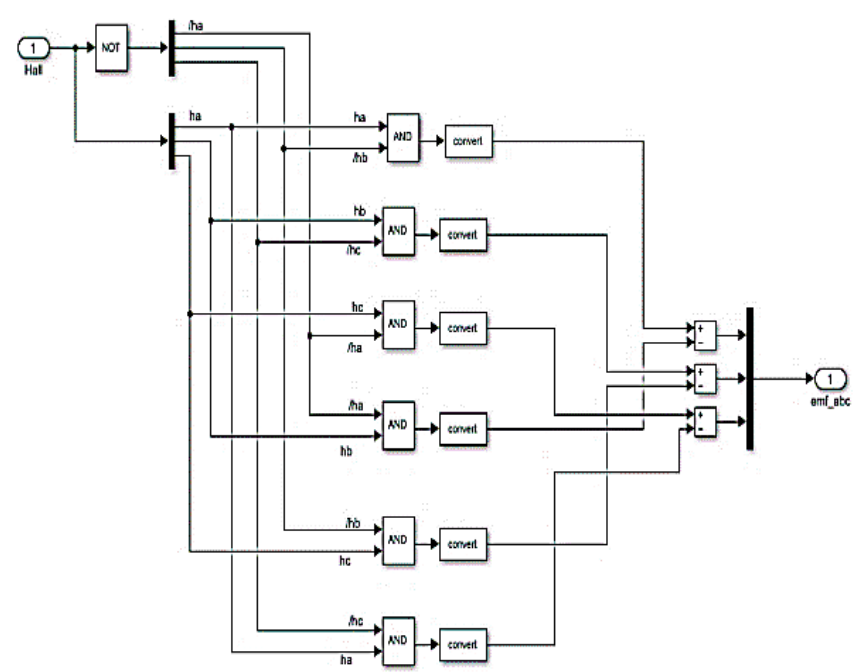

Fig 3. Back EMF of Decoder for MATLAB Drive.

TABLE I. TRUE TABLE FOR DECODER

\begin{tabular}{|l|l|l|l|l|l|l|}
\hline \multirow{3}{*}{ Table I. } & \multicolumn{6}{|l}{ True Table For Decoder } \\
\cline { 2 - 7 } & $\boldsymbol{h} \boldsymbol{a}$ & $\boldsymbol{h} \boldsymbol{b}$ & $\boldsymbol{h} \boldsymbol{c}$ & $\boldsymbol{e} \boldsymbol{m f \_} \boldsymbol{a}$ & $\boldsymbol{e} \boldsymbol{m f} \boldsymbol{b}$ & $\boldsymbol{e m f \_} \boldsymbol{c}$ \\
\hline 0 & 0 & 0 & 0 & 0 & 0 \\
\hline & 0 & 0 & 1 & 0 & -1 & +1 \\
\cline { 2 - 7 } & 0 & 1 & 0 & -1 & +1 & 0 \\
\cline { 2 - 7 } & 0 & 1 & 1 & -1 & 0 & +1 \\
\hline 1 & 0 & 0 & +1 & 0 & -1 \\
\hline 1 & 0 & 1 & +1 & -1 & 0 \\
\hline & 1 & 1 & 0 & 0 & +1 & -1 \\
\hline 1 & 1 & 1 & 0 & 0 & 0 \\
\hline
\end{tabular}

Similarly, Fig. 4 shows the functional block diagram of the inverter switching for MATLAB simulation, and Table II shows the decoder sequences of the proposed 3-phase PID controller for the BLDC motor to rotate in the counterclockwise motion.

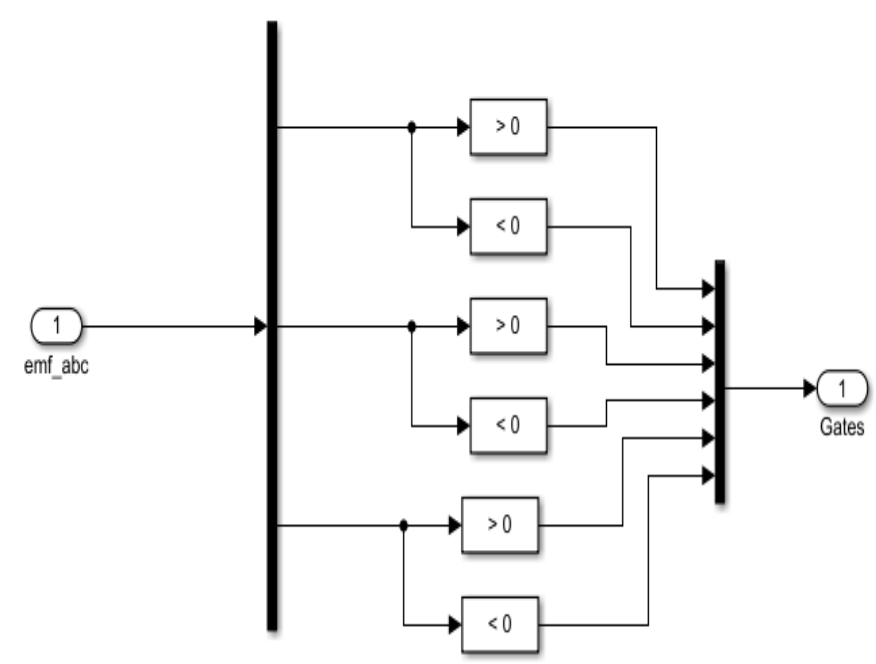

Fig 4. Inverter Switching for MATLAB Drive. 
TABLE II. TRUE TABLE FOR INVERTER SWITCHING

\begin{tabular}{|c|c|c|c|c|c|c|c|c|c|}
\hline \multirow{2}{*}{$\begin{array}{l}\text { Table } \\
\text { II. }\end{array}$} & \multicolumn{9}{|c|}{ True Table For Inverter Switching } \\
\hline & $e m f \_a$ & $e m f \_b$ & $e m f \_c$ & $Q 1$ & $Q 2$ & Q3 & Q4 & Q5 & Q6 \\
\hline & 0 & 0 & 0 & 0 & 0 & 0 & 0 & 0 & 0 \\
\hline & 0 & -1 & +1 & 0 & 0 & 0 & 1 & 1 & 0 \\
\hline & -1 & +1 & 0 & 0 & 1 & 1 & 0 & 0 & 0 \\
\hline & -1 & 0 & +1 & 0 & 1 & 0 & 0 & 1 & 0 \\
\hline & +1 & 0 & -1 & 1 & 0 & 0 & 0 & 0 & 1 \\
\hline & +1 & -1 & 0 & 1 & 0 & 0 & 1 & 0 & 0 \\
\hline & 0 & +1 & -1 & 0 & 0 & 1 & 0 & 0 & 1 \\
\hline & 0 & 0 & 0 & 0 & 0 & 0 & 0 & 0 & 0 \\
\hline
\end{tabular}

\section{Proposed PID CONTROLlER Modeling}

For getting better performance of DC motors it is essential to use a controller circuit. For this purpose, a variety of controller circuits and algorithms are used. However, among them PID controller is the most suitable controller circuit for BLDC motor. The PID controller is mainly composed of three block of circuits and they are proportional, integral and derivative blocks. Each block of circuit is used to perform different mathematical operations as their name mentioned. The complete MATLAB design of the proposed controller for 3-phase brushless DC motor is shown in Fig. 5. The diagram clearly shows how the reference source, PID controller, driver circuit, sensors, converter circuit, inverter circuit, display scope and motor are interconnected.

The foundational frequency transferring performance $G(\mathrm{~s})$ of the PID controller can be represented by (1) and (2),

$G(\mathrm{~s})=K_{p}+K_{i} / s+K_{d} s$

$\mathrm{G}(\mathrm{s})=(\mathrm{Kd} \mathrm{s} 2+\mathrm{Kp} \mathrm{s}+\mathrm{Ki}) / \mathrm{s}$

Where, $K_{p}=$ proportional gain coefficient, $K_{i}=$ integral gain coefficient, $K_{d}=$ derivative gain coefficient and $s$ is the complex frequency.

The time derivative output $U(\mathrm{t})$ of the controller for control of the plant is equal to $K_{p}$ times the magnitude of error pulse $K_{d}$ times the derivative of time function error signal $e(\mathrm{t})$ and $K_{i}$ times the integral can be represented by (3).

$\mathrm{U}(\mathrm{t})=\mathrm{Kp} \mathrm{e}(\mathrm{t})+\mathrm{Ki} \int \mathrm{e}(\mathrm{t}) \mathrm{dt}+\mathrm{Kd} \mathrm{de}(\mathrm{t}) / \mathrm{dt}$

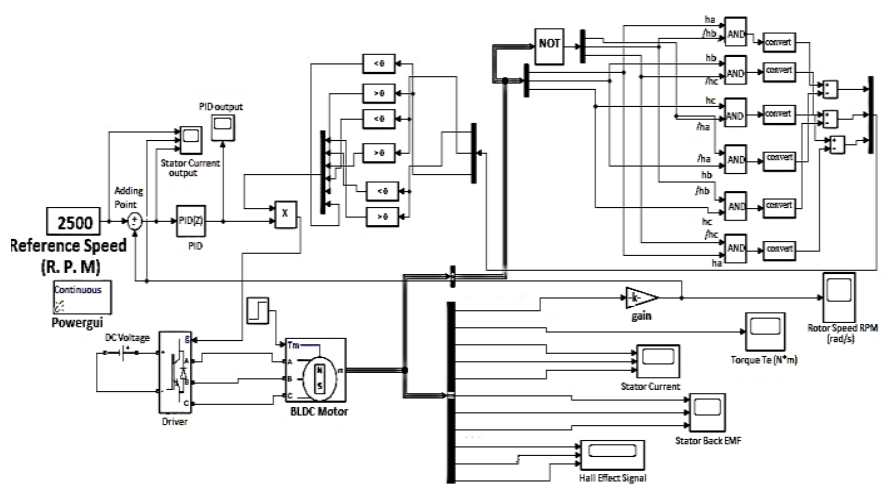

Fig 5. Complete MATLAB Design of Controller for BLDC Motor.
Its applications are wide because of its ease and outstanding performance, in many cases its efficiency is more than $95 \%$. Typically a closed-loop PID controller is used for industry application. The four key features are most interested in the response to the closed-loop step, they are, settling time, overshoot, steady-state error and response time.

Table III shows the values of the PID controller parameters used for this design.

TABLE III. VALUES OF THE PID CONTROLLER PARAMETERS

\begin{tabular}{|l|l|l|l|l|}
\hline \multirow{2}{*}{ Table III } & \multicolumn{4}{|l|}{ Values Of The PID Controller Parameters } \\
\cline { 2 - 5 } & Method & $\boldsymbol{K}_{\boldsymbol{p}}$ & $\boldsymbol{K}_{\boldsymbol{i}}$ & $\boldsymbol{K}_{\boldsymbol{d}}$ \\
\hline & PID & 100 & 0.5 & 500 \\
\hline
\end{tabular}

\section{RESULT AND DISCUSSION}

The performance of the proposed PID controller for brushless DC motor at $2500 \mathrm{rpm}$ is shown in Fig. 6. In this figure, $\mathrm{X}$ and $\mathrm{Y}$ axis represented the time in second (sec) and the speed (rpm) of the BLDC motor at no-load condition respectively. From the figure, it is seen that the settling time of the controller is about $0.018 \mathrm{sec}$ with a negligible amount of overshoot and undershoot. After $0.018 \mathrm{sec}$ the motor runs at a constant speed of the preset value $2500 \mathrm{rpm}$.

Fig. 7 shows the output torque response performance of the BLDC motor at no-load condition. In this figure, $\mathrm{X}$ and $\mathrm{Y}$ axis represented the time in second $(\mathrm{sec})$ and electromagnetic torque value in Newton-meter $(\mathrm{Nm})$ of the BLDC motor at noload condition, respectively. From the figure, it is observed that the motor electromagnetic torque $(\mathrm{Nm})$ is fixed after about $0.030 \mathrm{sec}$.

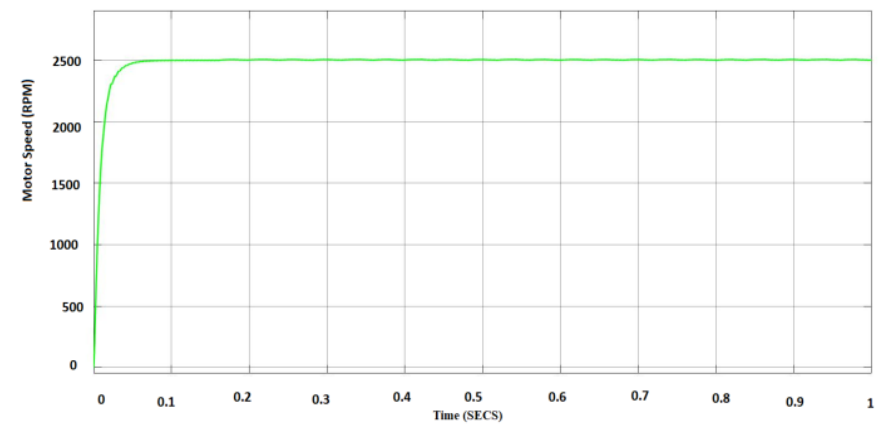

Fig 6. The no-load performance of the BDC motor using.

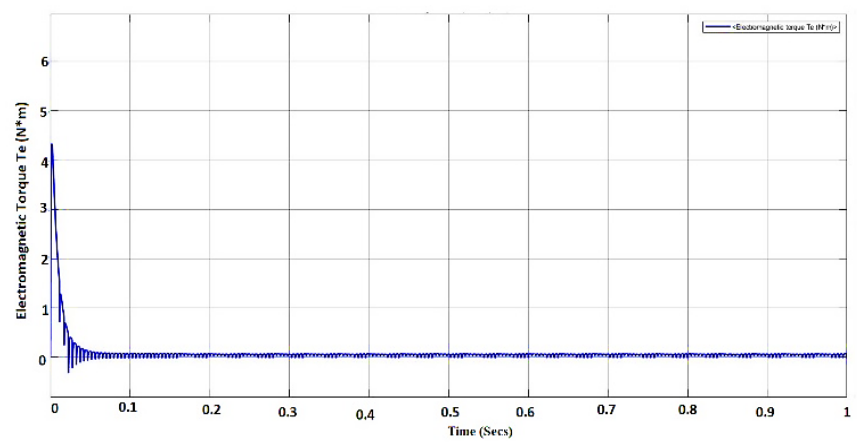

Fig 7. Time Versus Electromagnetic Torque Response of the BLDC Motor. 
Fig. 8 shows the stator current of the BLDC motor at noload condition. In this figure $\mathrm{X}$-axis represented the time in second (secs) and Y-axis the motor stator current in Ampere (A) respectively. In this figure the 3-phase stator currents are illustrated by the green, pink and yellow color lines respectively. It is also observed that the stators current are fixed after 0.030 (secs) which is the same as electromagnetic torque fixing time of the result as shown in Fig. 6.

Fig. 9 shows the back electromotive force (emf) of the BLDC motor at no-load condition. In this figure, $\mathrm{X}$ and $\mathrm{Y}$ axis represented the time in second (secs) and back emf value in Volt (V) of the BLDC motor at no-load condition respectively. The 3-phase back emf voltages of the BLDC motor are illustrated by the green, pink and yellow color lines in this figure, respectively. It is clear from the figure that the 3-phase back emf voltages are fixed $\pm 24 \mathrm{~V}$ after 0.030 (secs), which justifies the result same as the results obtained in Fig. 6 and Fig. 8.

Fig. 10 shows the 3-phase signals generated from Hallsensor. Here the green, pink and yellow color lines are represented the individual phase signal generated by the sensor.

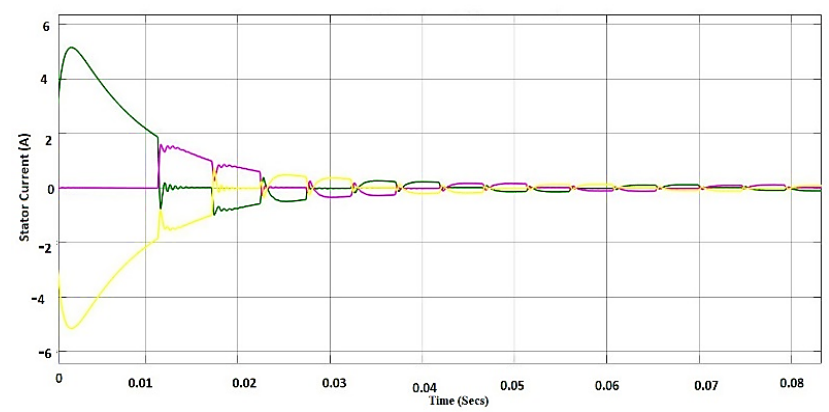

Fig 8. Phase Stator Current of the BLDC Motor

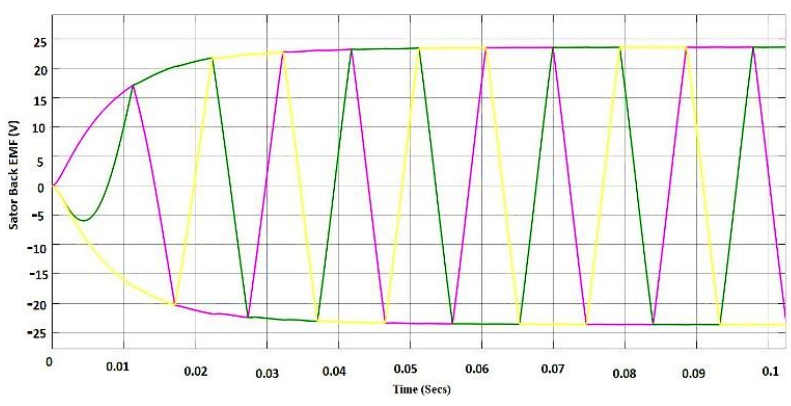

Fig 9. BLDC Motor 3-Phase Back Electromotive Force.

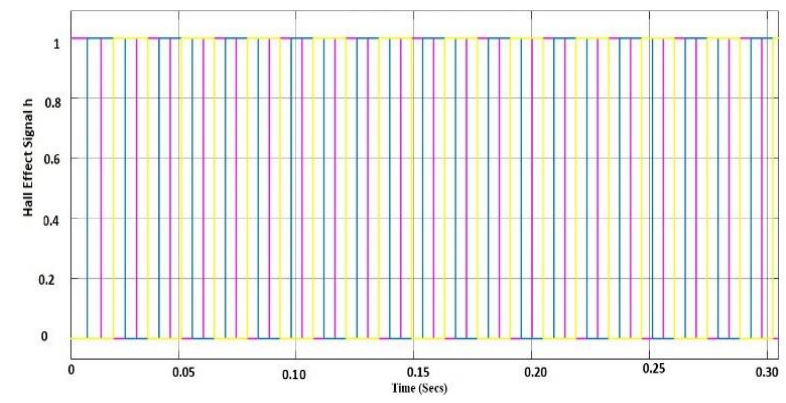

Fig 10. BLDC Motor Hall Effect Signal.
Fig. 11 shows the output performance of the PID controller. The $\mathrm{X}$-axis and $\mathrm{Y}$-axis represented the second (secs) and reference signal value in RPM of the PID controller, respectively. From the diagram, it is seen that the PID controller output under shoot and reach minimum value about $0.03 \mathrm{sec}$, then it reach at a stable condition after about $0.03 \mathrm{sec}$.

Fig. 12 shows the performance comparison of the PI, PID and Fuzzy logic controller. In this figure $\mathrm{X}$-axis and $\mathrm{Y}$-axis represented the time in second (secs) and electromagnetic torque value in Newton-meter $(\mathrm{Nm})$ of the BLDC motor at noload condition, respectively. Here, the red, yellow and green color lines are illustrated the PI, PID and Fuzzy logic controllers output performance in some respects. It is noteworthy that the performance of the PID controller is better than the other two controllers. The BLDC motor predetermined reference speed of $2500 \mathrm{rpm}$ has been chosen in this study.

From Fig. 6 and Fig. 12 it is observed that the PID controller settlement time about 18 milliseconds (msecs). The overshoots and undershoots of this controller are $0.4 \%$ and $1.9 \%$, respectively, which is within the tolerable range of a BLDC motor for suitable operation. The PID controller slew rate about 92.27 (msecs) and per shoot $2.5 \%$.

On the other hand, PI controller rise time is better than the PID controller but, its slow rate is much higher as 621.35 (msecs). In the other aspects of the PI controller, the pre-shoot $0.66 \%$, overshoot $32.67 \%$, undershoot $1.68 \%$ and settling time $15.20 \mathrm{msec}$. The pre-shoot, overshoot and undershoot are basically a high frequency nose and can be minimized by using filter [10].

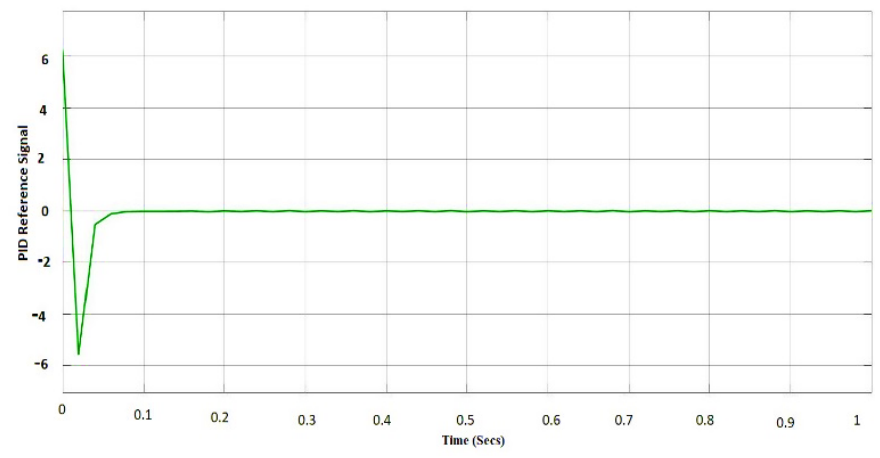

Fig 11. PID Controller Output Performance with Time.

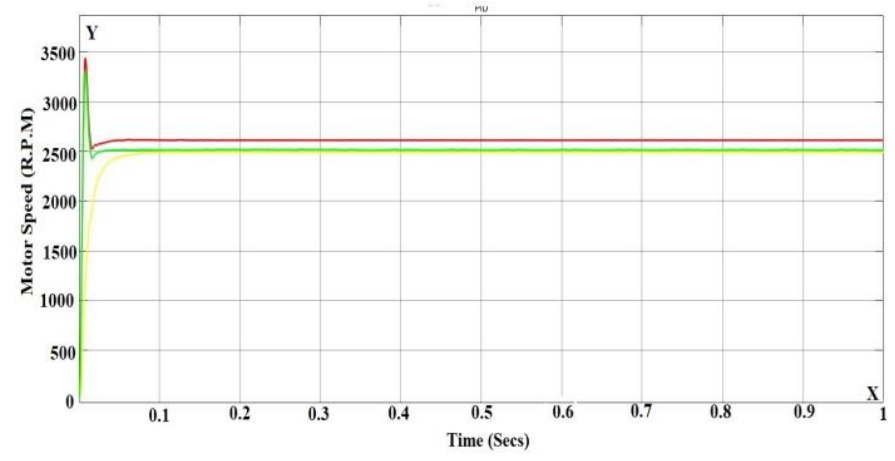

Fig 12. Performance Comparison among PI, PID and Fuzzy Logic Controllers. 
It shows that the output of the Fuzzy logic controller, the pre-shoot $0.67 \%$, slew rate 598.15 (msecs), overshoot $30.92 \%$, undershoot $3.2 \%$ and settling time 9.2 (msecs).

From comparative performance analysis it is understandable that the PID controller will provide the best results for BLDC motor control.

\section{CONCLUSION}

A three-phase BLDC motor controller has been successfully designed based on PID controller scheme and compared its performance with PI and Fuzzy logic controllers. From the results, it is observed that the PID controller provides the best performance compared to the other two controllers, PI and Fuzzy logic. The design has been validated by MATLAB simulation.

\section{ACKNOWLEDGMENT}

This research has been supported by the Malaysian Ministry of Education through the Fundamental Research Grant Scheme under the project ID: FRGS19-054-0662.

\section{REFERENCES}

[1] H. Salim Hameed, "Brushless DC Motor Controller Design Using Matlab Applications," 3rd Scientific Conference of Engineering Science (ISCES), 19 April 2018.

[2] M. Rajkumar, G. Ranjhitha, G. Pradeep and M. F. Kumar, "Fuzzy-based Speed Control of Brushless DC Motor feed electric vehicle," IJISSET, 2017, vol. 3(3).
[3] K. Swapnil, J. Anjali, A. Mohan and D. Shantanu, "Modeling and control of a permanent-magnet brushless DC motor drive using a fractional-order proportional-integral-derivative controller," Turkish Journal of Electrical Engineering and Computer Sciences, 2017, 25(5), pp. 4223-4241.

[4] M. Valan Rajkumar, G. Ranjhitha, M. Pradeep, M. Fasil PK and R. Sathish Kumar, "Fuzzy based Speed Control of Brushless DC Motor fed Electric Vehicle," International Journal of Innovative Studies in Sciences and Engineering Technology (IJISSET), 2017, vol. 3(3).

[5] H. Manal and Jasim, "Tuning of a PID Controller by Bacterial Foraging Algorithm for Position Control of DC Servo Motor," Iraqi Academic Scientific Journals, 2018, vol. 36.

[6] M. Singirala, D. Krishna and T. Anil Kumar, "Improving Performance Parameters of PMBLDC Motor using Fuzzy Sliding Mode Controller," International Journal of Recent Technology and Engineering (IJRTE), 2019, vol. 8(4).

[7] M. Rafay Khan, A. Ahmed Khan and U. Ghazali, "Speed Control of DC Motor under Varying Load Using PID Controller," International Journal of Engineering (IJE), 2015, vol. 9(3).

[8] T. Rahman, S. M. A. Motakabber, M. I. Ibrahimy and A. H. M. Zahirul Alam, "PLL-Based $3 \varphi$ Inverter Circuit for Microgrid System Operated by Electrostatic Generator," IIUM Engineering Journal, 2019, vol. 20(1), pp. 177-193.

[9] T. Rahman, S. M. A. Motakabber, M. I. Ibrahimy and Aliza 'Aini, "A PWM Controller of a Full Bridge Single-phase Synchronous Inverter for Micro-grid System," Journal of Physics: Conference Series, 2017, pp.113.

[10] S. M. A. Motakabber, M. A. Mohd Ali and N. Amin, "Computer Aided Design of an Active Notch Filter for HF Band RFID," FREQUENZ, 2010, vol. 64(1-2), pp. 23-25. 